\title{
TO STUDY THE BEHAVIOR OF NANOFLUIDS IN HEAT TRANSFER APPLICATIONS: A REVIEW
}

\author{
Chandra Prakash $^{1}$, Shri Ram², Kapil Sharma ${ }^{3}$, Parvinder Singh ${ }^{4}$ \\ ${ }^{1} P G$ Student, School of Mechanical Engineering, Lovely Professional University (LPU), Phagwara, Punjab, India \\ ${ }^{2} P G$ Student, School of Mechanical Engineering, Lovely Professional University (LPU), Phagwara, Punjab, India \\ ${ }^{3}$ Assistant Professor, School of Mechanical Engineering, Lovely Professional University (LPU), Phagwara, Punjab, \\ India \\ ${ }^{4}$ PG Student, School of Mechanical Engineering, Lovely Professional University (LPU), Phagwara, Punjab, India
}

\begin{abstract}
Using nanofluids as an innovative kind of liquid blend including trivial volume fraction (in percent) of millimeter or nanometer size powdered particles with base fluids is fairly a novel arena or idea. The objective of this presented review paper is to inspect the performance of the nanofluid-based solar collector (NBSC). In past few years for a number of experimental and industrial thermal engineering systems solar energy has proven to be the best input energy source. Nanofluids are the fluid that has shown various developments in the thermal properties over the past decade. In the field of nanotechnology, nano fluids have a great potential to enhance the rheological properties like thermal conductivity of base fluid like water, ethanol etc. Nanofluids are the suspension of mainly the base fluid like water in nanoparticles such as alumina $\left(\mathrm{Al}_{2} \mathrm{O}_{3}\right)$ of size micro or milimetre and shows distinctive features than that of conservative fluids used. Because of better rheological properties nanofluids are utilized to build up the performance of conventional solar thermal engineering systems. The presented literature review presents a detailed discussion about the solar collectors, applications of nanofluids in solar collector and their augmentation in thermo physical properties.
\end{abstract}

Keywords: Nano fluids, Nanoparticles, Solar collector, Thermal conductivity $* * *$

\section{INTRODUCTION}

The common examples of the non-renewable energy resources are coal, petroleum products, etc. and of renewable energy resources are tidal power, solar power, wind power, etc. There are many procedures and their related set up of equipments present for the generation of renewable energy. One the most useful technologies present for this purpose is the technology of solar concentrating collector. Solar concentrating collectors are the devices which uses a magnifying glass for generating solar energy in combination with absorber surfaces which can absorb the solar light coming from the sun. When all sunlight energy after spreading over magnifying glass surface focused on a point, it creates a drastic rise in the temperature. Due to this high temperature rise, a large amount of energy can be formed in form of heat energy.

In recent years, a tremendous growth in the energy sector especially in the area of energy in relation with solar applications is observed due to increased scientific developments. Several developments and examinations were carried out in the area of solar energy related with the scientific developments in the area of concentrated solar power (CSP). The solar energy is used to carry out the heating or cooling processes. For solar collectors the utilization of nanofluids as a working fluid is a relatively a novel idea. Various researchers are interested to develop the various aspects of solar energy because of it is readily available in nature.
Nano fluids exhibits excellent thermal properties when millimeter or micrometer sized solid particles of metals or non-metals getting mixed with base fluids such as water or ethyl alcohol in which they are in are scattered onto it. Due to their excellent properties they have found in various applications related to the heat transfer enhancement. The motive behind using nano fluids as thermo fluids is to enrich the heat transfer coefficient in heat exchangers, and also to minimize the dimension of heat transfer equipment's. Nano fluids assist to save the heat energy and material required for the heat exchanger. The essential parameters which influences the heat transfer characteristics in nano fluids are the properties named as viscosity, density, thermal conductivity and specific heat. The thermo substantial properties of nano fluids are mainly depend on the working temperatures.

In direction to upsurge the effectiveness or performance of solar collectors, one of the most appropriate method is to change the working fluid like water, ethylene glycol by higher thermal conductivity fluids like aluminum oxide, copper oxide. The blend of base fluids like water or ethylene glycol with suitable nanoparticles like silicon oxide or aluminium oxide are called nanofluids.

\section{LITERATURE REVIEW}

Nagarajan et al. [1] described nano fluid applications in solar collectors. He investigated his report on parabolic trough solar collectors. It was revealed that nano fluids used 
in the solar collectors enhance the effectiveness of the solar system. It was studied that use of nano fluids in the solar collectors encountered limitations such as particle agglomeration, erosion, stability, corrosion of heat transfer equipment's. It was also observed that the volume concentration and particle size plays a vital role in the effectiveness determination. Practical implications were influenced by factors such as production cost, synthesis methods and physical and chemical parameters. It was observed that the solar fuel with nanotechnologies in solar collector applications had enormous potential in future. It was also revealed that the property change strongly dependent on mass fraction, shape and size of nanoparticles. It was observed that there was not much improvement in properties of fluids. It was seen that the friction factor didn't play any role in improving heat transfer. Some of the researchers observed that concentration rate produce no or less effect in heat transfer coefficient rate.

Giorgio Cau [3] described a medium sized concentrating solar power (CSP) plants comparison based on parabolic and linear collectors. The performance of medium sized concentrating solar power plants was compared based on Organic Rankine Cycle (ORC) power generation unit combined with parabolic trough and linear Fresnel collectors. It was concluded that the performance assessment of concentrating solar power plants based on linear Fresnel collector lead to higher values of electrical energy production per unit area of land. It was observed that the highest specific energy production was 55-60 kWh/y per $\mathrm{m}^{2}$ square land occupied with solar multiples in range of 1.74-2.5 in 4-12 hours. The results revealed that linear Fresnel collectors are less expensive than parabolic trough collectors with lower optical efficiency. It was also observed that increase in solar multiple enhance the thermal energy output of solar field with required collecting and land area as well.

De Risi et al. [11] mathematically done the modelling and optimization of transparent parabolic trough collector based on gas-phase nanofluids as a working fluids. To directly absorb the solar energy a new concept of solar Transparent Parabolic trough Collector (TPTC) working with gas-based nanofluid as heat transfer fluid was suggested and examined. The model of the geometrical, thermal and fluid dynamic aspects of the TPTC was developed mathematically in order to attain global performance and to describe the main geometrical and operational parameters of the TPTC. In addition, to optimize the performance of the solar collector a genetic algorithm optimization was used.

Numerical results revealed that the gas-based nanofluids when combine with Transparent Parabolic trough Collector can be an effective substitute to conventional systems such as synthetic oils or molten salts. Simulation of the gas based nanofluids absorption showed that a complete absorption of the solar spectrum within the diameter of the receiver tube is attained by a correct mixture $(0.25 \% \mathrm{CuO}$ and $0.05 \% \mathrm{Ni})$. The results also indicated that the maximum TPTC solar to thermal efficiency is $62.5 \%$.for a nanofluid outlet temperature of $650^{\circ} \mathrm{C}$ and a nanoparticles volume concentration of $0.3 \%$.
Heimsath et al. [2] described the improvement in optical loss factors in linear concentrating collectors for process heat application. It was observed that the energy generation process was more effective in temperature range $423-573 \mathrm{~K}$. These concentrating collectors contained with concentrator and receiver. These were used for absorption of sun energy in combination with focal line. Tracking angles for a given position of sun direction were calculated. The reflected rays were transmitted by glass envelope, where part of intensity was lost due to absorption and reflection. These reflected rays were interacted with secondary reflector and redirected towards receiver. Material properties and geometrical optical errors were varied to show a range for optical collector efficiency. The effects due to shading on the receiver mirror field and acceptance of reflector were not considered negligible. The cosine losses, shading and blocking were very low at normal incidence for optimized linear Fresnel geometry. The difference between model tracing and model results were prominent about 30 Degree for low solar elevations. For high solar elevation, angle differences were occurred due to typical representation of shadowing effects. The influence of end loss was increasing with collector length and angles.

Chougule et al. [12] done experimental work to check the performance of solar water heater using solar tracking system using nanofluid as a working fluid. In this investigation two identical flat plate collectors using heat pipes were fabricated. The nanoparticles used in the present study are CNT having diameter 10-12 nm and for the preparation of nanofluid the concentration of nanoparticles taken as $0.15 \%$ by volume. Experimentations were carried in two steps i.e. by changing the collector's angle from Indian Standard i.e. normal angle $31^{\circ}$ to maximum performance angle of solar collector $50^{\circ}$ with fixed position and other step is keeping the collectors on tracking mechanism. The effect of tilt angle, Solar Tracking System, $\&$ effect on average efficiency and on heat loss factor $\left[\mathrm{T}_{\mathrm{m}}-\right.$ $\left.\mathrm{T}_{\mathrm{a}} / \mathrm{I}_{\mathrm{t}}\right]$ was observed.

After the observation of CNTs nanofluid used as working fluid it was concluded that a very low quantity of nanoparticles results in a better performance and has remarkable potential as working fluid in high performance thermosyphon heat pipe collectors. It was also concluded that at $50^{\circ}$ tilt angle working fluids gave better performance as compared to standard normal angle in both conditions (fixed and tracking) \& average efficiencies are increased $12 \%$ and $11 \%$ for water and nano working fluid at $31.50^{\circ}$ tilt angle while $7 \%$ and $4 \%$ respectively at $50^{\circ}$ tilt angle using tracking system, hence Solar tracking system adds an advantage to improve the efficiency in both water as well as nano working fluid solar heat pipe collector and also each of tilt angle for solar heat pipe collector.

Khullar et al. [13] carried out theoretical \& numerical investigation regarding the use of nanofluids as operational fluids in parabolic trough collector devices of concentrating type. In this paper mathematical modelling of heat transfer and flow aspects of the linear parabolic solar collectors had 
been done. Al nanoparticles were suspended in water and utilized as a operational nanofluid and to solve several equations numerically FDM (finite difference method) technique has been used. Evaluation and comparison of the two dimensional temperature field, optical and thermal efficiencies, and mean-outlet temperatures had been done for both conventional parabolic collectors utilizing water as a working fluid and nanofluid based collectors utilising nanofluid as a operational fluid. In order to achieve the desired output temperature the effect of various operating parameters such as concentration ratio, receiver length, fluid velocity, volume fraction of nanoparticles taken into consideration. The results indicated that in terms of thermal and optical efficiencies and higher outlet temperatures under same working conditions the collector using nanofluid as a working fluid has a better performance as compare to the conventional collector. The results also showed that the addition of aluminium nanoparticles into the base fluid (water) significantly improves its absorption characteristics.

Chamsa-ard et al [4] described thermal performance testing of heat pipe evacuated tube with compound parabolic concentrating (CPC) collector. Its purpose was to design, fabricate, test thermal efficiency of heat pipe evacuated tube. Its major advantage was that it can work without changing direction of CPC to track the sun. A mathematical model was developed for determining energy production base on radiation and ambient temperature data. The basic aim of this research was to develop the thermal performance of heat pipe displaced tube solar collector. The concept behind this was integrating CPC with displaced tube solar water collector and testing its performance. The system was heated by solar radiation incident on solar collector and transferred heat to water. All data of ambient temperature, output temperature, solar radiation and water flow rate were measured in time range of 10:00 to 12:00 in a day. The thermal efficiency and heat loss coefficients of CPC were measured $78 \%, 3.55$ and $0.0600 \mathrm{~W} / \mathrm{m}^{2}-\mathrm{C}$.

Maddah et al. [14] done practical examinations to study the effect of silver and aluminium oxide nanoparticles on rheological characeristics of thermos fluids i.e. nanofluids . Thermal conductivity, electrical conductivity, and viscosity are the thermo physical properties of nanofluids. For investigation the nominal diameters of $\mathrm{Al}_{2} \mathrm{O}_{3}$ and $\mathrm{Ag}$ nanoparticles taken as 40 and $20 \mathrm{~nm}$. Nanofluids of various volume concentrations $0.25 \%$ to $5 \%$ taken into consideration at a temperature of $15^{\circ} \mathrm{C}$. The nanofluid was prepared by dispersing aluminium oxide and silver nanoparticles in distilled water and then sonication process was done. The results revealed that:-

1. The viscosity and and heat transfer property i.e. conductivity of nanofluids increases as volume fraction of nanoparticles increases.

2. The electrical conductivity of thermo fluids rises as a straight line with a growth in the concentration in percentage of the aluminium oxide \& silver nanoparticles.
It was observed that higher the concentration of nanofluids, higher is the viscosity. On the other hand, electrical conductivity of aluminium oxide and silver nanofluid is significantly greater than that of the base fluid.

Gomes et al. [5] described the methods for asymmetric concentrating photovoltaic thermal (PVT) collectors producing heat and electricity both from the same area. It was revealed that the shading has more effect on PV than on thermal collectors. The improvements which were implemented were replacing reflective cables with transparent cables and to use different cell sizes. The main benefit found behind these improvements was to surge cell efficiency by decreasing cell operating temperature when hot water removed at low temperatures, to reduce the installation area and using the limited raw materials. It was found that concentrations achieve higher temperatures. In PV segments, solar cells were attached in series, thus entirely sheltered cells reduced the output of whole string. In thermal collectors, decrease in power produced was found directly proportional to the shaded area. It was revealed that in non-uniform radiation concentration in a string connected in series had a larger negative impact. The certain factors were found which affect the efficiency and performance of PVT collectors such as temperature of solar cells with upturn in solar irradiance which results in decrease in efficiency. The objective behind using PVT hybrid collectors was to upturn voltage and shrink current at higher irradiance levels and escaping capability constraints due to enlarged concentrations. Reflector material used was anodized aluminum with $95 \%$ reflectance. Once the cells were connected in series, the whole cell became shaded which resulted in decreased power of cells. It was concluded that larger cells reduced the cost of power generation. The effect of solar radiation on efficiency is shown in figure $1 \&$ figure 2 shows the effect of solar radiation on power power.

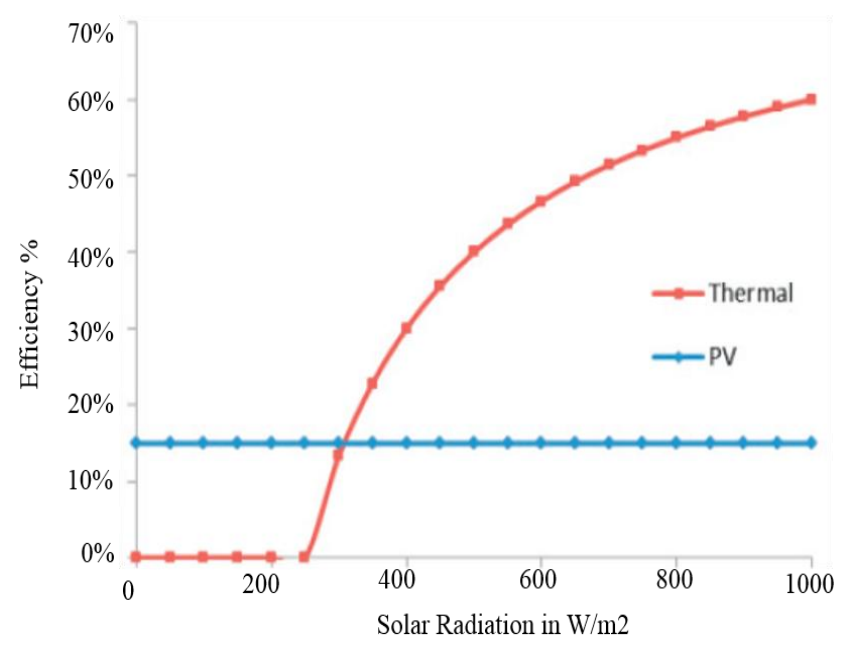

Fig 1: Effect of solar radiation on efficiency 


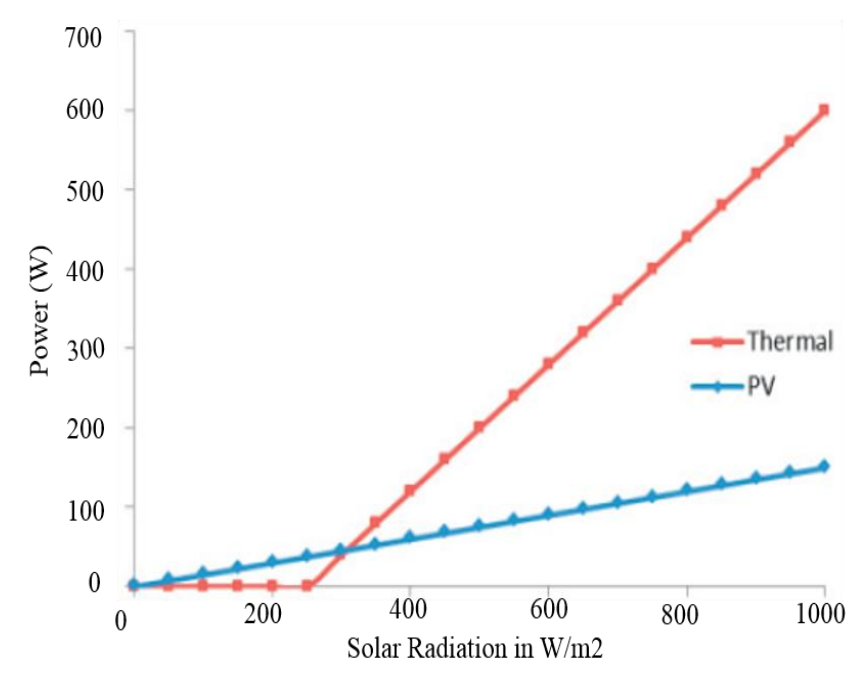

Fig 2: Effect of solar radiation power

J.M. Khodadadi [6] improves the change in the field of materials using the nanoparticle with the enormous prospective in support of improved thermal energy storage. They had use different governing equations in between nanoparticles and the base fluid used. They applied the SIMPLE technique using 6.2.16 version with the mercantile code and FLUENT was used for the utilization in the different governing equations. QUICK differencing scheme had been used for the energy and the momentum equation; on the other hand PRESTO scheme had been used for the pressure correction equation. They had compared functionality of the nanoparticle which is developing due to phase change materials to the base fluid. They had investigated the water with copper as Nano fluid inside the differentially heated square cavity and freeze the nanoparticles development of the phase change material. Grashof number was taken as $10^{4}$ and $10^{5}$ with the volume fraction of particle as $0,0.1$ and 0.2 respectively and with different time instants. High heat release rate has been found on nanoparticles enhanced phase change material as compare to the traditional phase change material with the high thermal conductivity so, that the proper utilization in the energy sector.

Wang et al. [7] present the review related to the description of heat transfer in nano fluid. The convective heat transfer can be progress inertly by the alteration in the thermal conductivity, change in the shape and boundary conditions. They mainly focus on the preparation of Nano fluids because it is the initial step for any experimental study. There must be some important requirement in preparation of Nano fluids are negligible agglomeration, stability, no compound alteration in fluids, durability of suspensions. They had summarizes different method used by the different researchers in their experimental work. The parameters associated with the heat transfer generally thermal conductivity, viscosity, convective heat transfer, boiling heat transfer of the Nano fluid with their measurement had been discussed in their work. Different analytical models were made and various numerical investigations were done by the researcher has been summarized. This paper shows a graph which compares the theoretical model versus the experimental data been generated for the thermal conductivity of $\mathrm{Al}_{2} \mathrm{O}_{3}$ with water as Nano fluids. Their research investigations were mainly resolute on the current conductivity reasonably than on the heat relocation feature.

K. Khanafer, K. Vafai [9] described fundamental synthesis of the thermo physical possessions of Nano fluids exists into their work. The effective thermal conductivity of Nano fluids and viscosity of nano fluids had been calculated by using the classical equations at room temperature and at low volume fractions. The effective viscosity of nano fluids is found to be decreases with increases in the temperature and increase with intensification in the volume fraction. The operational thermal conductivity of nano fluids decreases with intensification in the particle diameter and increases with intensification in temperature and also in volume fraction. Figure 3 shows the effect of volume concentration on the effective thermal conductivity measurements $\mathrm{CuO}$ water.

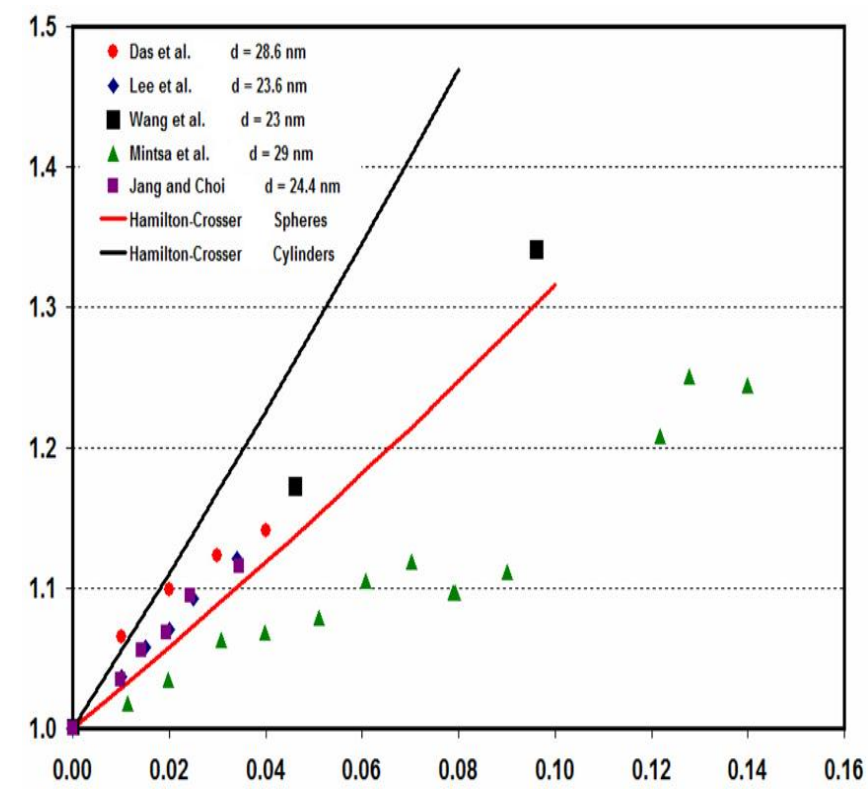

Fig 3: Effect of volume concentration on the effective thermal conductivity measurements $\mathrm{CuO}$-water [9]

Although the fact that the classical models was unable to calculate approximately the viscosity and operational thermal conductivity of nano fluids at different temperatures. Their study showed that we can't clear which diagnostic model has been used to illustrate the thermal conductivity of Nano fluids. The Correlations for viscosity and effective thermal conductivity are created and established in his study in expressions of relevant corporeal constraints based on the informed investigational data.

Nikkam et al. [8] worked experimentally and investigate the thermo physical properties on Nano fluid by the microwave assisted route. The Nano fluid prepared in their experiment was copper as a nanoparticles used and ethylene glycol as a base fluid. They studied the fabrication of $\mathrm{Cu}$ nanoparticles, with its thermal conductivity and some rheological features of the prepared Nano fluid. One step 
method has been used for the preparation of Nano fluid. For the characterization of the nanoparticles they use scanning electron microscopy and transmission electron microscopy technique. In their experiment work they set volume fraction from 0.4 to 1.6 weight percent and temperature is ranging from 20 to $50^{\circ}$. They compare their result with the appropriate model used and calculate the development in the thermal conductivity and value of viscosity. The results came out to be $7.2 \%$ improvement in the thermal conductivity with the mass concentration of $1.6 \%$ whereas in the case of viscosity there is $5.2 \%$. Figure 4 shows the Viscosity values for $\mathrm{Cu}-\mathrm{DEG}$ nano fluids (NFs), with different $\mathrm{Cu}$ nano particles (NPs) concentration ranging from $0.4 \mathrm{wt} \%$ to $1.6 \mathrm{wt} \%$, at $20^{\circ} \mathrm{C}$.

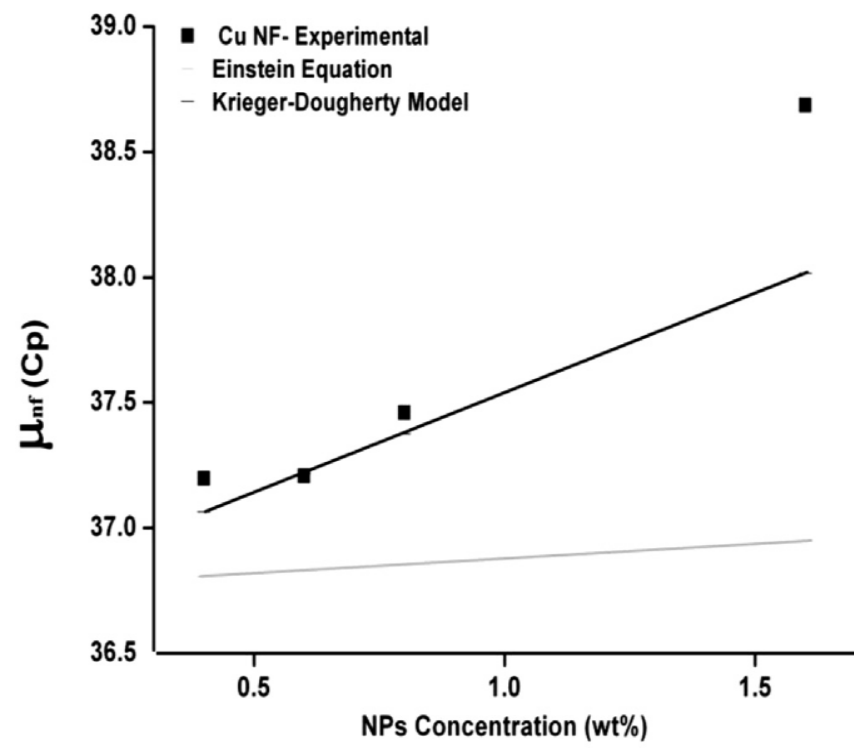

Fig 4: Viscosity values for Cu-DEG Nano fluids (NFs), with different $\mathrm{Cu}$ Nano particles (NPs) concentration ranging from $0.4 \mathrm{wt} \%$ to $1.6 \mathrm{wt} \%$, at $20^{\circ} \mathrm{C}$ [8]

R. Dharmalingam et al. [10] described Nano fluids as an innovative technology for heat transfer enhancement. It summarized the heat transfer in nano fluids. It was revealed that nanoparticles improved the thermal conductivity and convective heat transmission of liquids assorted with base fluids. It was examined that there was a disturbance in path and pressure drop in fluid with respect to the sedimentation, excessive wear and clogging by nano particles. Due to this, there were certain kinds of losses in the heat transfer properties were noticed. Nano fluids with different forms were identified as metal oxides, ceramics, metals, semiconductors and carbon Nano tubes. Proper dispersion of Nano fluids was done by the mixture of saturated water with Nano fluids provided with ultrasonic vibrations. The proper volume fraction was determined on the basis of true density and equivalent weight of the solids provided with ultrasonic vibrations. It was observed that with increase in temperature the dynamic viscosity decreases. Due to this thermal conductivity of Nano fluids found to be higher. Here due to solar energy unsteady state flow was studied which was found to be dependent on angle of inclination of porous wedge. The temperature absorption was found more with high density of Nano fluid in comparison with water. It was revealed that with decrease in fluid flow velocity with increase of unsteady parameter. Figure 5 shows the volume weighted particle size distribution for $\mathrm{Al}_{2} \mathrm{O}_{3}$ particles.

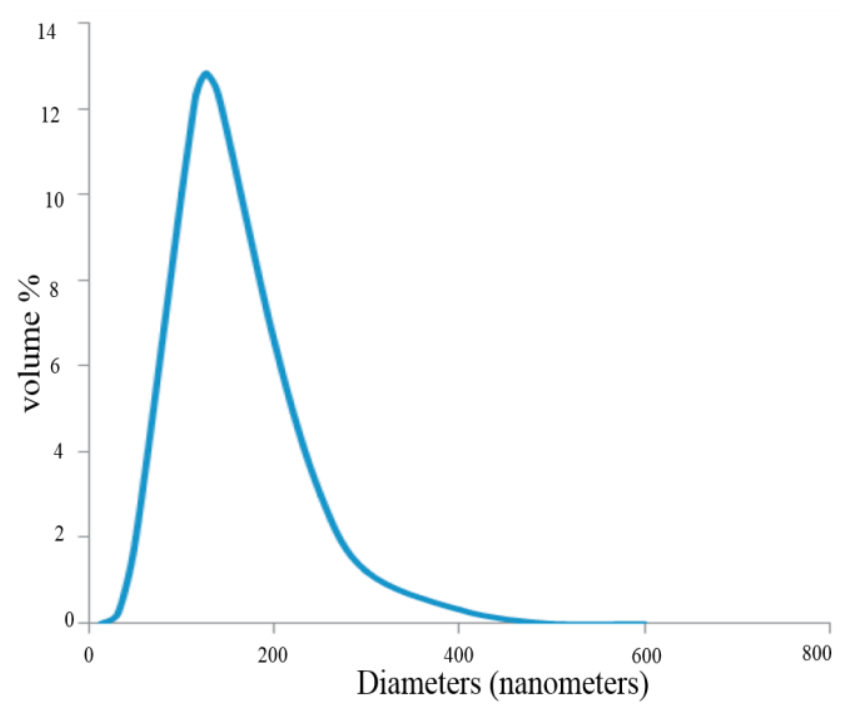

Fig 5: volume weighted particle size distribution for $\mathrm{Al}_{2} \mathrm{O}_{3}$ particles

Khullar et al. [15] studied the ecological influence of thermo fluid based focused heat energy system using solar energy as a source. This presented review paper investigates the capability of nanofluid-based concentrating solar water heating system as a substitute to schemes rely on coal, oil . Therefore, to save fossil fuels which are presently being widely used for water heating purposes the concept of NCSWHS and its potential was examined. It was found that the proposed water heating system has relatively better performance characteristics in comparison with the conventional flat plate collectors. The NCSWHS system also seems to be the best solution for fuel savings and it also promises the reduction of $\mathrm{CO}_{2}$ emission so far as it substitutes for fossil fuel water heaters. It was seen that:-

1. The common water heating system of concentrating type would be more efficient and cost effective than flat plate collector.

2. The main advantage of NCSWHS is that it is being energy efficient.

3. Higher output temperatures can be attained by using NCSWHS hence it significantly reduces greenhouse gas emissions and save enormous amount of fossil fuels.

\section{CONCLUSION}

Nano fluids are used in different applications which are mainly related to the transfer of heat. The problem arises in Nano fluid is with the settling of nanoparticles, erosion and agglomeration of the nanoparticles. It has been observed that the heat transfer in the solar collectors depends upon the factors like shape, ray tracing angle etc.

Modelling and optimization of transparent parabolic trough collector based on gas-phase nanofluids was also carried out and the numerical results have shown that gas-based 
nanofluids combined with TPTC can be an effective alternative to conventional systems such as synthetic oils or molten salts that have shown different application problems in existing plants. Simulations results also show that that the maximum TPTC solar to thermal efficiency is $62.5 \%$, for a nanofluid outlet temperature of $650{ }^{\circ} \mathrm{C}$ and a nanoparticles volume concentration of $0.3 \%$.

\section{REFERENCES}

[1]. P. K. Nagarajan, J. Subramani, S. Suyambazhahan, R. Sathyamurthy (2014), Nanofluids for solar collector applications, "International conference of Applied Energy", Vol. 61, pp. 2416-2434.

[2]. A. Heimsath, G. Bern, D.V. Rooyen, P. Nitz (2014) Quantifying optical loss factors of small linear concentrating collectors for process heat application, "2nd International Conference on Solar Heating and Cooling for Buildings and Industry “, Vol. 48,pp. 77-86.

[3]. G. Cau, D. Cocco (2014), Comparison of medium-size concentrating solar power plants based on parabolic trough and linear Fresnel collectors, "68th Conference of the Italian Thermal Machines Engineering Association”, Vol. 45, pp. 101-110.

[4]. W. C. Ard, S. Sukchai, S. Sonsaree, C. Sirisamphanwong (2014), Thermal Performance Testing of Heat Pipe Evacuated Tube with Compound Parabolic Concentrating Solar Collector, "Eco-Energy and Materials Science and Engineering”, Vol. 56, pp. 237-246.

[5]. J. Gomes, L. Diwan, R. Bernardo, B. Karlsson (2014), Minimizing the Impact of Shading at Oblique Solar Angles in a Fully Enclosed Asymmetric Concentrating PVT Collector, "Energy Precedia", Vol. 57, pp. 2176-2185.

[6]. J.M. Khodadadi, S.F. Hosseinizadeh (2007), Nanoparticle-enhanced phase change materials (NEPCM) with great potential for improved thermal energy storage, "International Communications in Heat and Mass Transfer", Vol. 34, issue 5, pp 534-543.

[7]. X. Q. Wang, A. S. Mujumdar (2007), Heat transfer characteristics of nanofluids, "International Journal of Thermal Sciences”, Vol. 46, issue 1, pp. 1-19.

[8]. N. Nikkam, M. Ghanbarpour, M.saleemi, E.B. Haghighi, R. Khodabandeh, M. Muhammed, B. Palm, M. S. Toprak (2014), Experimental investigation on thermophysical properties of copper/ diethylene glycol nanofluids fabricated via microwave-assisted route, "Applied Thermal Engineering”, Vol. 65, pp. 158-165.

[9]. K. Khanafer, K. Vafai (2011), A Critical Synthesis of Thermophysical Characteristics of Nanofluids, "International Journal of Heat and Mass Transfer", Vol. 54, issue 19-20, pp. 4410-4428.

[10]. R. Dharmalingama, K. K. Sivagnanaprabhub, B. S. kumarc R. Thirumalaid (2014), Nano materials and nanofluids: An innovative technology study for new paradigms for technology enhancement, "12th global congress on manufacturing and management”, Vol. 97, pp. 1434-1441.

[11]. De Risi A., Milanese M., Laforgia D.,(2013), Modelling and optimization of transparent parabolic trough collector based on gas-phase nanofluids, "Renewable Energy", Vol. 58,pp.134-139.

[12]. Chougule Sandesh S., Pise Ashok T., Madane Pravin A.,(2012), Performance of nanofluid charged solar water heater by solar tracking system, In: Proceedings of "IEEEInternational Conference On Advances In Engineering, Science And Management (ICAESM -2012)" March 30, 31,2012,pp.247-253.

[13]. Khullar V., Tyagi H., (2010), Application of nanofluids as the working fluid in concentrating parabolic solar collectors, "37th National \& 4th International Conference on Fluid Mechanics \& Fluid Power", IIT Madras, Chennai, India, Dec. 16-18, Paper No. FMFP2010179.

[14]. Maddah H., Rezazadeh M., Maghsoudi M., NasiriKokhdan S., (2013), The effect of silver and aluminium oxide nanoparticles on thermophysical properties of nanofluids, "Journal of Nanostructure in Chemistry", Vol. 3, pp.1-6.

[15]. Khullar V., Tyagi H., (2012), A study on environmental impact of nanofluid based concentrating solar water heating system, "International Journal of Environmental Studies”, Vol. 69, issue 2, pp. 220-232.

\section{BIOGRAPHIES}

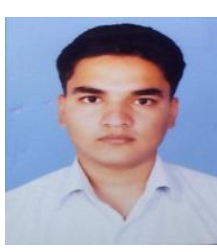

Mr. Chandra Prakash, PG Student, Lovely Professional University, Jalandhar (Punjab).

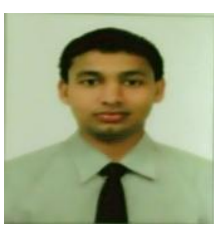

Mr. Shri Ram, PG Student, Lovely Professional University, Jalandhar (Punjab).

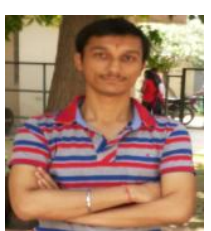

journal.

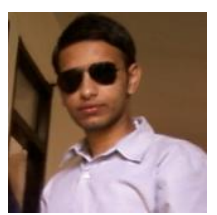

Mr. Kapil Sharma, Assistant professor (A.P.) in Mechanical Engineering Department at Lovely Professional University, Jalandhar (Punjab).He has two and half years of teaching experience. He has published one paper in international

Mr. Parvinder Singh, PG Student, Lovely Professional University, Jalandhar (Punjab). 